\author{
Marquette University \\ e-Publications@Marquette
}

School of Dentistry Faculty Research and

Publications

Dentistry, School of

3-2009

\title{
Erosive Tooth Wear Among Children in the United States: Relationship to Race/Ethnicity and Obesity
}

Jesse McGuire

Marquette University

Aniko Szabo

Medical College of Wisconsin

Scott Jackson

Medical College of Wisconsin

T. Gerard Bradley

Marquette University, thomas.bradley@marquette.edu

Christopher Okunseri

Marquette University, christopher.okunseri@marquette.edu

Follow this and additional works at: https://epublications.marquette.edu/dentistry_fac

Part of the Dentistry Commons

\section{Recommended Citation}

McGuire, Jesse; Szabo, Aniko; Jackson, Scott; Bradley, T. Gerard; and Okunseri, Christopher, "Erosive Tooth Wear Among Children in the United States: Relationship to Race/Ethnicity and Obesity" (2009). School of Dentistry Faculty Research and Publications. 97.

https://epublications.marquette.edu/dentistry_fac/97 
Marquette University

e-Publications@Marquette

\section{Dentistry Faculty Research and Publications/School of Dentistry}

This paper is NOT THE PUBLISHED VERSION; but the author's final, peer-reviewed manuscript. The published version may be accessed by following the link in the citation below.

International Journal of Paediatric Dentistry, Vol. 19, No. 2 (March 2009): 91-98. DOI. This article is (C) Wiley and permission has been granted for this version to appear in e-Publications@Marquette. Wiley does not grant permission for this article to be further copied/distributed or hosted elsewhere without the express permission from Wiley.

\section{Erosive Tooth Wear Among Children in The United States: Relationship to Race/Ethnicity and Obesity}

Correction(s) for this article Corrigendum Volume 19 Issue 3 International Journal of Paediatric Dentistry pages: 222-222 First Published online: April 7, 2009

Jesse Mcguire Department of Developmental Sciences, Marquette University School of Dentistry, Milwaukee, WI Aniko Szabo Division of Biostatistics, Department of Population Health, Medical College of Wisconsin, Milwaukee, WI

Scott Jackson

Division of Biostatistics, Department of Population Health, Medical College of Wisconsin, Milwaukee, WI

T. Gerard Bradley

Department of Developmental Sciences, Marquette University School of Dentistry, Milwaukee, WI 


\section{Christopher Okunseri}

Department of Clinical Services, Marquette University School of Dentistry, Milwaukee, WI

\section{Abstract}

Objective. The study aims were to estimate the prevalence of erosive tooth wear (ETW) in children and to specifically examine its association with race/ethnicity and obesity in the United States.

Design. We analysed data from the National Health and Nutrition Examination Survey (NHANES), 2003-2004. ETW was measured using the modified Smith and Knight Tooth Wear Index derived from the 1998 United Kingdom Adult Health Survey.

Results. This study shows that $45.9 \%$ of children aged 13-19 years had evidence of ETW in at least one tooth. The prevalence of ETW was bilaterally symmetrical in all teeth examined and was most prevalent in maxillary teeth. Females had significantly lower rates of ETW of any tooth compared to males. African Americans had significantly lower rates of ETW (except in the canines), and Hispanics had similar rates compared to whites. Compared to 'healthy weight' children, those 'at risk for overweight' had lower rates of ETW and the 'overweight' groups had higher rates, but results were not significant.

Conclusions. Substantial proportions of children in the US are affected by ETW. Compared to whites, African American children had significantly lower rates of ETW. Although not significant, 'overweight' (obese) children had increased odds of having ETW and those at 'risk for overweight' had lower odds compared to 'healthy weight' children.

\section{Introduction}

Clinicians and epidemiologists have commonly described non-carious, pathological loss of tooth tissue as 'erosion', 'abrasion', and 'attrition' depending on the aetiological factors associated with the loss of tooth surface $^{1}$. Smith and Knight, however, prefer the use of the term 'tooth wear' as a reflection of all three conditions in relation to the aetiological factors ${ }^{1,2}$. For ease of exposition, we will use the terms 'erosive tooth wear (ETW)' or 'dental erosion' interchangeably throughout this paper, because it has been acknowledged that the major cause of tooth wear in children is erosion ${ }^{3}$. In addition, the term 'ETW' used in this paper is consistent with the training and calibration of examiners, as well as with the survey instrument used in data collection. Early signs of ETW are changes in the optical properties of enamel that results in a smooth silky-shining glazed surface $^{4}$. Dental erosion is the chemical dissolution of dental hard tissues by intrinsic or extrinsic acids, without bacterial involvement ${ }^{5,6}$. It is one of the forms in which tooth wear occurs in primary and permanent dentition ${ }^{7}$, and can affect any tooth surface, but is most often seen on the facial, occlusal, and lingual tooth surfaces ${ }^{8}$.

Studies have reported on the aetiology of dental erosion and its association with caries, enamel hypoplasia, dietary habits, fruit intake, socioeconomic factors, toothbrushing habits, fluoridation, and demographic factors (such as age, gender, and social class) ${ }^{8-13}$. However, some of the evidence supporting these assertions are nonconclusive and have come from small studies using convenience samples. In addition, epidemiological surveys conducted in the United Kingdom have shown that the prevalence of dental erosion ranged between $7 \%$ and $56 \%$ depending on the tooth type, surface examined, age, survey instrument used, and the training and calibration of examiners ${ }^{14,15}$. In the United States, dental erosion has not been shown to be a prevalent condition $^{16}$, presumably due to the differences in how clinicians measure and record ETW and the lack of a population-based study on the condition. The decline in tooth loss due to caries and periodontal disease has made dental erosion to become gradually recognized as a public health concern especially among children and adolescents in the United Kingdom, Republic of Ireland, and Australia.

In the United States, there is a significant increase in the prevalence of childhood obesity, reaching almost epidemic proportions ${ }^{17}$. Childhood obesity has been associated with the number of servings of fruit juice and 
soft drinks ingested each day, and also with increased caries ${ }^{18}$. Soft drinks contain carbonic and phosphoric acids, and have the potential to directly cause the chemical dissolution of tooth enamel, particularly if the teeth are periodically exposed to a diet drink throughout the day ${ }^{18}$. Although some information on the link between dental erosion and the increased consumption of soft drinks is available, the relationship between obesity and erosion is completely lacking. This information is particularly important to dentists for appropriate targeting of at-risk children and for identification of those with the greatest need for prevention and treatment.

To date, no study has examined whether dental erosion is associated with race/ethnicity and obesity using a national representative sample in the United States. The aims of this study were to estimate the prevalence of dental erosion and to specifically examine whether race/ethnicity and obesity are associated with dental erosion in children. Findings from this study will help raise awareness about early diagnosis of dental erosion and identification of associated risk factors by dental professionals, given the growing concern about dental erosion among clinicians and public health scientists ${ }^{19}$.

\section{Methods}

We analysed data from the National Health and Nutrition Examination Survey (NHANES), 2003-2004. This is the first cycle where the oral examination component included a measurement of tooth wear (dental erosion) among subjects 13 years and older in the United States. NHANES in 2003-2004 is a nationwide representative sample of children in which 1962 children aged 13-19 were examined for any evidence of dental erosion. The survey instrument used to measure dental erosion was the modified Smith and Knight Tooth Wear Index (TWI), derived from the 1998 United Kingdom Adult Dental Health Survey ${ }^{20,21}$. The protocol development and training for measuring tooth wear involved international collaborators including researchers and oral epidemiologists from the United Kingdom and the Republic of Ireland. Extensive details on NHANES 2003-2004 methodologies, training, and calibration of examiners are provided elsewhere ${ }^{21}$. Dental erosion was assessed for all the incisors, and canines, as well as for the first molars. A visual examination of the facial, lingual, and incisal surfaces of the anterior teeth, as well as the occlusal surfaces of molar teeth was done ${ }^{21}$. Tooth wear scores (TWS) were based upon the extent of enamel loss and dentin exposure for each eligible tooth surface ${ }^{21}$.

Codes were as follows: (i) TWS 0 refers to no obvious wear facets in enamel, occlusal/incisal structure intact. (ii) TWS 1 refers to marked wear facets in enamel, occlusal/incisal structure altered. (iii) TWS 2 refers to wear into dentin, dentin exposed occlusally/incisally, or occlusal/incisal changed in shape (or both). (iv) TWS 3 refers to extensive wear into dentin, greater than $2 \mathrm{~mm}^{2}$ of exposed dentin occlusal/incisal, and occlusal/incisal structure totally lost, locally or generally.

\section{Study variables}

No child had a TWS of 3, and a very small number had a score of 2 , so these were combined with 1 . Thus, the outcome variable of erosion measures any dental erosion. Other variables included were: age in years (treated as continuous), body mass index (BMI) category (underweight, healthy weight, risk of overweight, and overweight) classified based on age and gender-specific percentiles defined by the Centers for Disease Control and Prevention ${ }^{22}$, last dental visit (within the last year or not), race/ethnicity (white, African American, Hispanic, and other), and gender. This study was approved by the Institutional Review Board of Marquette University.

\section{Statistical analysis}

Descriptive statistics and survey weighted estimates were performed. Multivariable regression was performed to examine several different outcomes: whether or not dental erosion was present anywhere in a patient's mouth, as well as whether dental erosion was present on four different types of teeth (molars, canines, lateral incisors, and central incisors). The general analysis approach followed the NHANES analytical guidelines in adjusting for the survey design ${ }^{23}$. The analysis was performed using SAS 9.1.3 (SAS Institute, Cary, NC, USA) using 
PROC SURVEYFREQ and PROC SURVEYLOGISTIC as appropriate. An alpha level of 0.05 was used throughout to denote statistical significance.

\section{Results}

Table 1 shows the unweighted and weighted frequencies of the study population characteristics. Non-Hispanic whites constituted $65 \%$ of the study population, and Hispanics and African Americans accounted for approximately $16 \%$ and $15 \%$, respectively; $50 \%$ were males. The age distribution was approximately uniform, with an average age of 16 years, whereas $68 \%$ of the population had dental insurance. Almost three-quarters of the study population were from families whose income was over $\$ 20000$ per year, and a similar proportion had not visited a dental office in the past year.

Table 1. Unweighted and weighted frequencies of characteristics of US children with erosive tooth wear (dental erosion): National Health and Nutrition Examination Survey: 2003-2004.

\begin{tabular}{|c|c|c|c|}
\hline Population characteristics & $\begin{array}{l}\text { Unweighted } \\
\text { frequency }\end{array}$ & $\begin{array}{l}\text { Weighted frequency } \\
\text { (in millions) }\end{array}$ & $\begin{array}{l}\text { Weighted percent } \\
\text { (SE) }\end{array}$ \\
\hline \multicolumn{4}{|l|}{ Gender } \\
\hline Male & 1002 & 14.4 & $50.1(1.3)$ \\
\hline \multicolumn{4}{|l|}{ Age (years) } \\
\hline $13-15$ & 821 & 12.4 & $43.1(1.9)$ \\
\hline $16-17$ & 573 & 8.0 & $28.0(2.0)$ \\
\hline $18-19$ & 568 & 8.3 & $28.9(2.6)$ \\
\hline \multicolumn{4}{|l|}{ Race/Ethnicity } \\
\hline Hispanic & 666 & 4.7 & $16.3(3.2)$ \\
\hline White & 534 & 18.6 & $64.6(4.4)$ \\
\hline African American (Black) & 701 & 4.3 & $14.9(2.3)$ \\
\hline Other & 61 & 1.2 & $4.2(0.8)$ \\
\hline \multicolumn{4}{|l|}{ Income } \\
\hline Under $\$ 20000 /$ year & 515 & 5.6 & $19.6(3.0)$ \\
\hline Over \$20 000/year & 1311 & 21.3 & $74.1(3.0)$ \\
\hline Unknown & 136 & 1.8 & $6.3(0.9)$ \\
\hline \multicolumn{4}{|l|}{ Dental coverage } \\
\hline Not covered & 199 & 4.0 & $13.9(1.7)$ \\
\hline Covered & 1303 & 19.6 & $68.1(2.3)$ \\
\hline Unknown & 460 & 5.2 & $18.0(1.7)$ \\
\hline \multicolumn{4}{|l|}{ BMI category } \\
\hline Underweight & 54 & 0.8 & $2.9(.7)$ \\
\hline Healthy weight & 1187 & 17.6 & $61.4(2.4)$ \\
\hline Risk of overweight & 338 & 5.0 & $17.5(1.5)$ \\
\hline Overweight & 359 & 5.1 & $17.7(1.6)$ \\
\hline Unknown & 24 & 0.02 & $0.6(0.2)$ \\
\hline \multicolumn{4}{|l|}{ Last dental visit } \\
\hline Less than 1 year ago & 643 & 7.4 & $25.8(2.0)$ \\
\hline More than 1 year ago & 1316 & 21.3 & $74.2(2.0)$ \\
\hline Unknown & 3 & 0.02 & $0.07(0.04)$ \\
\hline
\end{tabular}




\section{Prevalence of dental erosion by tooth type/location}

Overall, $45.9 \%$ of American children age 13-19 have dental erosion in at least one tooth (data not shown). Among the tooth surfaces, the highest rate of erosion was observed on the incisal surface of the incisors, canines, and the occlusal surfaces of the molars; the erosion rate of the facial and lingual surfaces was very small $(<0.5 \%)$. Prevalence of dental erosion was almost bilaterally symmetrical in the maxillary and mandibular teeth. Teeth of the same type (central incisor, lateral incisor, canine, first molar) in the same arch had similar rates of dental erosion, and dental erosion was more prevalent in the lower than upper teeth (Table 2). For subsequent analyses, the presence of any surfaces with TWS of 1 or above (i.e. the 'Any' column in Table 2) was used as a tooth-specific measurement of dental erosion. Prevalence of dental erosion was observed as highest in the lower right and left central incisors $(28.6 \%, 26.9 \%)$, and lowest in the upper right first molars (3.2\%).

Table 2. Percentage (SE) of tooth surfaces with erosive tooth wear (dental erosion).

\begin{tabular}{|l|l|l|l|l|l|}
\hline Tooth \#/Type & Facial & Incisal & Lingual & Occlusal & Any \\
\hline Upper teeth right & & & & & \\
\hline 03 First molar & & & & $3.2(0.7)$ & $3.2(0.7)$ \\
\hline 06 Canine & $0.2(0.1)$ & $12.4(1.9)$ & $0.1(0.1)$ & & $12.5(1.9)$ \\
\hline 07 Lateral & $0.1(0.1)$ & $8.3(1.9)$ & $0.3(0.2)$ & & $8.4(1.8)$ \\
\hline 08 Central & $0.2(0.1)$ & $19.2(3.7)$ & $0.4(0.2)$ & & $19.2(3.7)$ \\
\hline Upper teeth left & & & & & \\
\hline 09 Central & $0.2(0.1)$ & $19.5(3.8)$ & $0.5(0.2)$ & & $19.6(3.8)$ \\
\hline 10 Lateral & $0.1(0.1)$ & $7.1(1.6)$ & $0.3(0.2)$ & & $7.2(1.6)$ \\
\hline 11 Canine & $0.2(0.2)$ & $13.0(1.8)$ & $0.2(0.2)$ & & $13.2(1.8)$ \\
\hline 14 First molar & & & & $4.2(0.8)$ & $4.2(0.8)$ \\
\hline Lower teeth left & & & & & $19.2(2.9)$ \\
\hline 19 First molar & & & & 19.2 & $19.2(2.2)$ \\
\hline 22 Canine & $0.05(.03)$ & $11.6(2.2)$ & $0.02(0.02)$ & & $11.8(3.0)$ \\
\hline 23 Lateral & $0.2(0.2)$ & $14.96(3.0)$ & $0.1(0.1)$ & & $15.26 .9(5.1)$ \\
\hline 24 Central & $0.2(0.2)$ & $26.5(5.1)$ & $0.1(0.1)$ & & $28.6(5.8)$ \\
\hline Lower teeth right & & & & & $14.6(3.0)$ \\
\hline 25 Central & $0.2(0.2)$ & $28.2(5.7)$ & $0.1(0.1)$ & & $10.3(1.9)$ \\
\hline 26 Lateral & $0.2(.2)$ & $14.3(3.0)$ & $0.2(0.2)$ & & $14.7(2.6)$ \\
\hline 27 Canine & $0.06(.04)$ & $10.1(1.9)$ & $0.02(0.02)$ & & $14.7(2.6)$ \\
\hline 30 First molar & & & & & \\
\hline & & & & & \\
\hline
\end{tabular}

\section{Univariate analyses of factors associated with dental erosion}

Significant gender differences exist in the percentage of children with dental erosion with lower prevalence in girls by 3.6-9.5\% (based on values in Table 3). The percentage of children with dental erosion increased significantly with age and was associated with children who had made a dental visit in the last year. Whites, Hispanics, and those of other race/ethnicity had a significantly higher percentage of dental erosion in comparison with African American children. Dental insurance, income, and obesity were not significantly associated with dental erosion. 
Table 3. Univariate analyses of erosive tooth wear and teeth type in the maxilla and mandible.

\begin{tabular}{|c|c|c|c|c|c|c|c|c|c|}
\hline Characteristic & $\begin{array}{l}\text { Maxillary } \\
\text { teeth } \\
\text { examined } \\
\text { percentage } \\
\text { (SE) }\end{array}$ & & & & $\begin{array}{l}\text { Mandibular } \\
\text { teeth examined } \\
\text { percentage (SE) }\end{array}$ & & & & $P$ value $*$ \\
\hline & $\begin{array}{l}\text { Central } \\
\text { incisor }\end{array}$ & $\begin{array}{l}\text { Lateral } \\
\text { incisor }\end{array}$ & Canine & First molar & Central incisor & Lateral incisor & Canine & First molar & \\
\hline Gender & & & & & & & & & 0.0013 \\
\hline Male & $30.6(5.8)$ & $18.8(3.7)$ & $14.7(2.7)$ & $19.6(2.8)$ & $22.2(4.4)$ & $10.7(2.3)$ & $17.6(2.5)$ & $5.5(1.2)$ & \\
\hline Female & $25.0(5.4)$ & $11.1(2.9)$ & $7.4(1.8)$ & $13.9(2.9)$ & $16.7(3.8)$ & $4.9(1.4)$ & $8.1(1.9)$ & $1.9(0.7)$ & \\
\hline Age (years) & & & & & & & & & 0.0001 \\
\hline $13-15$ & $23.2(4.9)$ & $10.6(2.4)$ & $5.6(1.3)$ & $9.7(2.2)$ & $15.1(2.7)$ & $5.7(1.2)$ & $7.4(1.3)$ & $1.6(0.5)$ & \\
\hline $16-17$ & $27.7(6.7)$ & $16.1(4.2)$ & $13.4(2.5)$ & $20.1(4.0)$ & $19.7(5.3)$ & $7.6(1.9)$ & $12.9(2.3)$ & $4.7(1.3)$ & \\
\hline $18-19$ & $34.9(6.8)$ & $20.4(4.5)$ & $17.2(3.8)$ & $25.3(4.0)$ & $25.9(5.1)$ & $11.2(2.8)$ & $20.7(3.3)$ & $6.1(1.5)$ & \\
\hline Dental visit & & & & & & & & & 0.04 \\
\hline$<1$ year ago & $35.6(5.8)$ & $18.5(3.4)$ & $13.3(2.2)$ & $18.7(2.5)$ & $22.4(4.4)$ & $7.3(1.9)$ & $13.7(2.6)$ & $4.9(1.3)$ & \\
\hline$>1$ year ago & $25.0(5.4)$ & $13.7(3.0)$ & $10.3(2.2)$ & $16.3(3.0)$ & $18.4(3.8)$ & $8.0(1.9)$ & $12.6(2.0)$ & $3.3(0.8)$ & \\
\hline BMI category & & & & & & & & & 0.6 \\
\hline Underweight & $26.6(10.6)$ & $18.2(7.3)$ & $11.5(5.4)$ & $22.4(7.4)$ & $24.3(9.9)$ & $7.5(4.0)$ & $13.5(6.9)$ & $9.4(5.8)$ & \\
\hline Healthy weight & $28.6(5.7)$ & $14.9(3.2)$ & $11.0(2.2)$ & $17.9(2.9)$ & $19.6(3.9)$ & $8.4(1.9)$ & $12.4(1.8)$ & $4.2(0.9)$ & \\
\hline Risk of overweight & $30.8(6.2)$ & $15.6(2.6)$ & $10.1(2.2)$ & $16.7(3.8)$ & $21.4(3.6)$ & $7.2(1.6)$ & $13.7(2.4)$ & $1.6(1.0)$ & \\
\hline Overweight & $21.5(4.9)$ & $14.0(3.7)$ & $12.5(3.5)$ & $11.7(2.3)$ & $16.0(3.7)$ & $6.5(2.3)$ & $13.7(3.0)$ & $3.4(1.2)$ & \\
\hline Dental insurance & & & & & & & & & 0.16 \\
\hline Covered & $25.7(5.3)$ & $13.6(2.9)$ & $9.6(2.0)$ & $16.0(2.8)$ & $17.9(3.6)$ & $7.1(1.7)$ & $11.1(1.6)$ & $2.8(0.6)$ & \\
\hline Not covered & $28.3(7.2)$ & $13.7(4.3)$ & $14.8(4.0)$ & $20.2(4.9)$ & $20.4(5.7)$ & $8.0(2.6)$ & $17.7(4.5)$ & $8.5(3.2)$ & \\
\hline Race/Ethnicity & & & & & & & & & 0.011 \\
\hline White & $30.8(6.4)$ & $16.0(3.5)$ & $11.6(2.5)$ & $18.3(3.2)$ & $19.9(4.1)$ & $8.3(2.0)$ & $13.2(2.1)$ & $4.3(1.0)$ & \\
\hline African American & $15.8(4.0)$ & $9.5(2.5)$ & $8.7(2.2)$ & $8.7(2.1)$ & $10.7(3.2)$ & $4.6(1.1)$ & $10.1(2.2)$ & $1.6(0.6)$ & \\
\hline Hispanic & $27.6(5.7)$ & $16.0(3.4)$ & $10.6(1.8)$ & $19.6(3.2)$ & 24.5 (4.9) & $8.9(1.7)$ & $13.1(2.5)$ & $3.5(1.0)$ & \\
\hline Other & $23.7(10.8)$ & $13.3(6.5)$ & $13.2(4.7)$ & $13.6(4.1)$ & $22.5(9.3)$ & $6.9(3.9)$ & $15.6(3.9)$ & $2.9(1.7)$ & \\
\hline Income & & & & & & & & & 0.37 \\
\hline$<\$ 20000$ & $32.2(6.9)$ & $16.0(3.3)$ & $12.4(2.5)$ & $18.7(3.1)$ & $23.5(4.8)$ & $7.1(1.7)$ & $14.0(2.5)$ & $3.5(1.0)$ & \\
\hline$>\$ 20000$ & $26.6(5.5)$ & $14.2(2.9)$ & $10.9(2.3)$ & $16.4(2.9)$ & $17.8(3.6)$ & $8.1(1.7)$ & $12.7(2.1)$ & $3.9(1.0)$ & \\
\hline
\end{tabular}

$* P$ values refer to whether the covariate is associated with differential erosion in any tooth type. 


\section{Multivariable analysis of factors associated with dental erosion}

We conducted separate multivariable logistic regression analyses for tooth-type specific outcome variables defined as the presence of dental erosion in any central incisor, any lateral incisor, any canine, any first molar, or any tooth overall (Table 4). In general, the results of the multivariate analysis are similar to those of the univariate analysis. Dental erosion increased with age for all tooth types; for each increase of 1 year in age, the odds of erosion increased by 1.1-1.3 times, depending on tooth type. Overall, underweight adolescents had the lowest probability of having a tooth with dental erosion. The children 'at risk for overweight' had lower odds, and the 'overweight' groups had higher odds of dental erosion compared to the 'healthy weight' group.

However, this was not statistically significant. Among the specific tooth types, this effect is strongest in the canines, with a similar pattern that is, however, not statistically significant for the lateral and central incisors. The molars, however, show a different pattern: the lowest rate of dental erosion in the first molars is in the 'at risk for overweight' group. Note that this group tends to have lower dental erosion probability than the reference group of 'healthy weight' for all the other tooth types as well. African Americans had the least amount of dental erosion for all tooth types (although the effect is not statistically significant for the canines). The other racial/ethnic groups had dental erosion rates that were not statistically different from whites. Females had significantly less erosion than males for every type of surface and all tooth types. 
Table 4. Logistic regression analyses for the different tooth type with erosive tooth wear.

\begin{tabular}{|c|c|c|c|c|c|}
\hline Characteristic & $\begin{array}{l}\text { OR }(95 \% \mathrm{Cl}) \text { of dental } \\
\text { erosion in any teeth } \\
\text { examined }\end{array}$ & $\begin{array}{l}\text { OR }(95 \% \mathrm{Cl}) \text { of } \\
\text { dental erosion in } \\
\text { molars }\end{array}$ & $\begin{array}{l}\text { OR }(95 \% \mathrm{Cl}) \text { of } \\
\text { dental erosion in } \\
\text { canines }\end{array}$ & $\begin{array}{l}\text { OR }(95 \% \mathrm{Cl}) \text { of } \\
\text { dental erosion in } \\
\text { lateral incisors }\end{array}$ & $\begin{array}{l}\text { OR }(95 \% \mathrm{Cl}) \text { of } \\
\text { dental erosion in } \\
\text { central incisors }\end{array}$ \\
\hline Age (years) & $1.17(1.07,1.29)$ & $1.30(1.18,1.42)$ & $1.31(1.19,1.44)$ & $1.19(1.05,1.33)$ & $1.13(1.01,1.27)$ \\
\hline \multicolumn{6}{|l|}{ BMI category } \\
\hline Underweight & $0.44(0.22,0.90)$ & $0.90(0.42,1.95)$ & $0.45(0.24,0.86)$ & $0.85(0.35,2.08)$ & $0.69(0.31,1.56)$ \\
\hline Overweight & $1.19(0.83,1.71)$ & $0.95(0.62,1.46)$ & $1.01(0.70,1.45)$ & $1.21(0.93,1.58)$ & $1.23(0.81,1.87)$ \\
\hline Risk of overweight & $0.81(0.62,1.07)$ & $0.61(0.43,0.88)$ & $0.91(0.62,1.34)$ & $0.98(0.70,1.35)$ & $0.70(0.46,1.06)$ \\
\hline Healthy weight & 1.00 (reference) & 1.00 (reference) & 1.00 (reference) & 1.00 (reference) & 1.00 (reference) \\
\hline \multicolumn{6}{|l|}{ Last dental visit } \\
\hline$>1$ year ago & $0.71(0.55,0.92)$ & $0.90(0.64,1.25)$ & $0.76(0.49,1.17)$ & $0.81(0.57,1.14)$ & $0.55(0.42,0.72)$ \\
\hline$<1$ year ago & 1.00 (reference) & 1.00 (reference) & 1.00 (reference) & 1.00 (reference) & 1.00 (reference) \\
\hline \multicolumn{6}{|l|}{ Race/Ethnicity } \\
\hline African American & $0.47(0.28,0.78)$ & $0.40(0.27,0.58)$ & $0.72(0.39,1.34)$ & $0.50(0.28,0.91)$ & $0.40(0.23,0.70)$ \\
\hline Hispanic & $1.00(0.59,1.70)$ & $1.09(0.69,1.73)$ & $1.09(0.65,1.83)$ & $1.10(0.60,2.00)$ & $0.79(0.40,1.56)$ \\
\hline Other & $0.86(0.45,1.67)$ & $0.68(0.38,1.21)$ & $1.52(0.72,3.23)$ & $0.89(0.34,2.33)$ & $0.64(0.22,1.77)$ \\
\hline White & 1.00 (reference) & 1.00 (reference) & 1.00 (reference) & 1.00 (reference) & 1.00 (reference) \\
\hline \multicolumn{6}{|l|}{ Sex } \\
\hline Female & $0.56(0.40,0.78)$ & $0.55(0.43,0.70)$ & $0.40(0.25,0.65)$ & $0.59(0.41,0.86)$ & $0.72(0.54,0.97)$ \\
\hline Male & 1.00 (reference) & 1.00 (reference) & 1.00 (reference) & 1.00 (reference) & 1.00 (reference) \\
\hline
\end{tabular}




\section{Discussion}

We found that $46 \%$ of children (equivalent to 9 in 20 children) aged 13-19 years had some evidence of dental erosion in at least one tooth. A study conducted in Maryland using a convenience sample of 129 children aged 11-13 years reported that prevalence of dental erosion was $41 \%^{14}$. In our study, prevalence of erosion in 13 years old was $37 \%$ (data not shown). Our result is slightly lower, but the difference in prevalence reported from both studies could be due to intra- and inter-variability of examiners in the TWI used, sampling methods, and regional variation. Furthermore, this study is the first to report on the prevalence of dental erosion from a nationally representative sample of children in the United States. Both studies, however, confirm anecdotal evidence that dental erosion is prevalent in the United States in similar magnitudes to the United Kingdom and Australia ${ }^{7,15}$. Therefore, it is important for dentists to participate in early diagnosis, and educate parents and children on the prevention of dental erosion and treatment strategies to reduce the associated complications.

We found that dental erosion increased with age, and for each increase of 1 year in age, the odds of a child having dental erosion increased by as much as 1.3 times for all teeth examined. With erosion considered an irreversible condition, this trend of increased odds with age is not entirely surprising, but a reminder that if a condition is left unchecked it will progress to adulthood. This finding supports similar results from other studies in developed countries that have either used a convenience sample, small sample sizes, or a national database $\mathrm{e}^{10,12,13}$.

Compared to males, females were significantly less likely to have dental erosion for every tooth type and surface examined, which supports findings from other studies $4,8,15,16$. Additionally, adult males tend to have greater dental erosion that progresses and becomes a continuous erosive process through adulthood ${ }^{15}$. However, few studies reported no significant gender difference in dental erosion ${ }^{14}$.

Compared to children who visited a dental office over a year ago, children who visited within the last year were significantly more likely to have dental erosion in any teeth examined. Although there are no studies published that have examined this association identified in our study, we suggest that further investigation be conducted to better understand the link between last dental visits and dental erosion. This is particularly important to elucidate whether dentists participate in early diagnosis and seek to educate parents and children on prevention and treatment strategies for erosion.

Although various studies have reported on the aetiology and factors associated with dental erosion, our study is the first to specifically examine whether race/ethnicity is associated with dental erosion from a representative sample in the United States. We found that African Americans were significantly less likely than whites to have dental erosion on all teeth examined except in the canines. Hispanics, however, were almost as likely as whites to have dental erosion, but this was not significant for all teeth examined. A study of 1753 children aged 12 years drawn from all 62 state-maintained schools in Leicestershire in the United Kingdom indicates that a higher proportion of Caucasians showed dental erosion than other ethnic groups in the United Kingdom ${ }^{24}$. Our results are similar to findings from the UK study, and therefore, demonstrate that whites are substantially more affected by dental erosion than other minority groups.

Studies have described the association of dietary, carbonated, and fruit juice intake with dental erosion. However, no study has examined specifically the relationship between childhood obesity (known to be associated with the number of servings of fruit juice and soft drinks ingested each day) and dental erosion ${ }^{13}$. Overall, we found that underweight adolescents had the lowest probability of having a tooth with dental erosion. The 'at risk for overweight' and the 'overweight' groups were considered almost similar to the 'healthy weight' group. Future studies examining this relationship are required to give dentists the ability to actually say whether obesity could be a risk factor for dental erosion in population groups. 
Certain study strengths and limitations should be noted. The study used the very first set of nationally representative children's data available from the NHANES 2003-2004 protocol to describe the prevalence of dental erosion and its associated factors. The study provides comparison with the national UK study based on the fact that similar TWI was used ${ }^{20}$. Findings from this study are particularly important to paediatric dental professionals especially in the United States for the purpose of diagnosing dental erosion at an early age, and for formulating a risk assessment protocol for identifying and managing associated risk factors. In summary, 46\% (9 in 20) children aged 13-19 had some evidence of dental erosion in at least one tooth, ETW increased with age, and females had significantly less ETW compared to males for every tooth type and surface examined. African Americans had a significantly lower percentage of dental erosion for most tooth types (except canines), and obesity was not significantly associated with an increase in ETW in children in the United States.

\section{Acknowledgements}

The authors wish to thank Dr Cesar Gonzalez for his constructive comments during the initial development of the protocol. We thank Emily McGinley for her help in retrieving data from the NHANES database.

\section{What this paper adds}

- This paper provides the first empirical data from a national representative sample in the United States to support the growing concern among paediatric dentists that ETW is gradually becoming a public health problem.

\section{Why this paper is important to paediatric dentists}

- This paper raises awareness among United States paediatric dentists that the prevalence of ETW in children is substantially higher than was previously thought to be, and that there is a need for early diagnosis, treatment, and prevention.

- This paper provides a platform for paediatric dental professionals to formulate risk assessment protocols for identifying and managing patients who are considered at risk for developing ETW.

\section{References}

1 Kelleher M, Bishop K. Tooth surface loss: an overview. Br Dent J 1999; 186: 61- 66.

2 Smith BGN, Knight JK. An index for measuring the wear of teeth. Br Dent J 1984; 156: 435- 438.

3 Millward A, Shaw L, Smith A. Dental erosion in 4-year-old children from differing socio-economic backgrounds. J Dent Child 1994; July-August: 263- 266.

4 Ganss C. How valid are current diagnostic criteria for dental erosion? Clin Oral Invest 2008; 12: S41- S49.

5 Pindborg J. Pathology of Dental Hard Tissues. Copenhagen: Munksguard, 1970: 312.

6 Linnett V, Seow WK. Dental erosion in children: a literature review. Pediatr Dent 2001; 23: 37- 43.

7 Bartlett DW, Shah P. A critical review of non-carious cervical (wear) lesions and the role of abfraction, erosion, and abrasion. J Dent Res 2006; 85: 306- 312.

8 Williams D, Croucher R, Marcenes W, O'Farrell M. The prevalence of dental erosion in the maxillary incisors of 14-year-old school-children living in Tower Hamlets and Hackney, London, UK. Int Dent J 1999; 49: 211- 216.

9 Kazoullis S, Seow WK, Holcombe T, Newman B, Ford D. Common dental conditions associated with dental erosion in schoolchildren in Australia. Pediatr Dent 2007; 29: 33- 39.

10 Milosevic A, Young $P$, Lennon $M$. The prevalence of tooth wear in 14-year-old schoolchildren in Liverpool. Community Dent Health 1993; 11: 83-86.

11 Deery C, Wagner ML, Longbottom C, Simon R, Nugent ZJ. The prevalence of dental erosion in a United States and a United Kingdom sample of adolescents. Pediatr Dent 2000; 22: 505- 510. 
12 Dugmore CR, Rock WP. The prevalence of tooth erosion in 12-year-old children. Br Dent J 2004; 196: 279- 282.

13 Al-Dlaigan YH, Shaw L, Smith A. Dental erosion in a group of British 14-year-old, school children. Part I: prevalence and influence of differing socioeconomic backgrounds. Br Dent J 2001; 190: 145- 149.

14 Walker A, Gregory J, Bradnock G, Nunn J, White D. National Diet and Nutrition Survey: Young People Aged 4 to 18 Years. London: HMSO, 2000.

15 Hinds K, Gregory JR. National Diet and Nutrition Survey: Children Aged 11/2 to 41/2 Years, Vol. 2: Report of the Dental Survey. London: HMSO, 1995.

16 Bartlett D, Phillips K, Smith B. A difference in perspective - the North American and European interpretation of tooth wear. Int J Prosthodont 1999; 12: 401- 408.

17 Centers for Disease Control and Prevention. NHANES Data on the Prevalence of Overweight Among Children and Adolescents: United States, 2003-2004. CDC National Center for Health Statistics, Health E-Stat. [WWW document.]

URL http://www.cdc.gov/nchs/products/pubs/pubd/hestats/overweight/overwght_child_03.htm (acces sed: 04 August 2008).

18 Karp WB. Oral Health. [WWW document.] URL http://www.faqs.org/nutrition/Ome-Pop/OralHealth.html (accessed: 04 August 2008).

19 Lussi A. Erosive tooth wear - a multifactorial condition of growing concern and increasing knowledge. Monogr Oral Sci 2006; 20: 1-8.

20 Kelly M, Steele J, Nuttall N, et al . Adult Dental Health Survey: Oral Health in the United Kingdom 1998. London: Office for National Statistics, 1998.

21 Dye BA, Nowjack-Raymer R, Barker LK, et al . Overview and quality assurance for the oral health component of the National Health and Nutrition Examination Survey (NHANES) 2003-2004. American Association of Public Health Dentistry 2008. doi: 10.1111/j.1752-7325.2007.00076.x

22 Division of Nutrition Physical Activity and Obesity. National Center for Chronic Disease Prevention and Health Promotion. Department of Health and Human Services. Centers for Disease Control and Prevention. [WWW document].

URL: http://www.cdc.gov/nccdphp/dnpa/healthyweight/assessing/bmi/childrens_BMI/about_childrens _BMI.htm (accessed: 04 August 2008).

23 Centers for Disease Control and Prevention. Analytic and Reporting Guidelines. National Health and Nutrition Examination Survey (NHANES). [WWW document].

URL: http://www.cdc.gov/nchs/data/nhanes/nhanes_03_04/nhanes_analytic_guidelines_dec_2005.pdf (accessed: 3 August 2008).

24 Dugmore CR, Rock WP. A multifactorial analysis of factors associated with dental erosion. Br Dent J 2004; 196: 283- 286. 